\title{
DESAFIOS DA FORMAÇÃo CONTÍNUA A DISTÂNCIA PARA PROFESSORES DE CIÊNCIAS
}

\author{
(CHALLENGES FACED BY SCIENCE TEACHERS IN CONTINUING \& DISTANCE EDUCATION)
}

Paulo Sérgio Garcia

Nelio Bizzo

Faculdade de Educação da Universidade de São Paulo, Brasil

Xavier Fazio

Brock University, Faculty of Education, Canada

\section{RESUMO}

Este estudo investigou as características pessoais, as preocupações, os desafios do processo de estudo e os investimentos (esforços) de um grupo de professores de ciências que participou, com sucesso, de cursos de formação contínua a distância (FCD) em uma universidade pública. Os dados foram coletados por meio de entrevistas e analisados qualitativamente com a utilização de códigos e descritores. Autonomia, motivação, disciplina e responsabilidade foram algumas características pessoais encontradas nesta pesquisa. Preocupações relacionadas às exigências da formação, às expectativas em relação ao sucesso no curso, ao processo de interação, aos conhecimentos adquiridos e às tecnologias foram catalogadas. Os maiores desafios enfrentados pelos professores para conduzir, de forma satisfatória, o processo de estudo a distância estão relacionados com a organização, a disciplina e a autonomia. Os resultados mostraram, por fim, que são necessários investimentos intelectuais e emocionais para participar desse tipo de formação. Esses dados podem auxiliar os formadores na gestão do curso, assessorando os professores ao longo da FDC e potencializando suas aprendizagens.

Palavras-chave: formação contínua, professores de ciência, educação a distância.

\section{ABSTRACT}

This study examines the personal characteristics, the current concerns, and the challenges of academic study. In addition, it examines the investment (efforts) of science teachers who participated in distance continuing education courses (DCEC) within a public university. Data were collected from interviews and then analyzed qualitatively using codes and descriptors. Autonomy, motivation, discipline and responsibility were some of the key characteristics of the teachers evaluated in this study. Concerns regarding training needs, students' expectations 
with regard to their success in the course, the interaction process, the acquired skills, and the technologies used, were identified and later recorded on paper. The greatest challenges faced by professors in successfully managing the distance education process were related to personal study skills (organization), personal discipline, and autonomy. Finally, the results show that intellectual and emotional effort is required to participate in this type of online training. Furthermore, the findings from this study may facilitate course management trainers, thereby assisting DCEC professors during the entire learning process, and maximize the potential of science education.

Keywords: Continuing Education, Science Teacher Education, Distance Education.

Na Educação a Distância (EAD) professores e alunos estão fisicamente separados, há flexibilidade para os períodos de estudo, a aprendizagem acontece no ritmo do aluno e por suas habilidades próprias, mediadas pela ação e pela cooperação dos outros, e o processo de ensino e aprendizagem ocorre por meio da utilização de diferentes tecnologias digitais, como, por exemplo, a internet.

Esta modalidade de ensino, na medicação do processo de ensino e aprendizagem, tem potencial para contribuir com a formação contínua de professores de ciências, auxiliando na formação do professor e elevando o nível da qualidade do Ensino de Ciências (Garcia, 2011). Este autor mostrou que a formação contínua a distância de professores de ciências não é uma opção e sim uma realidade para os problemas e dificuldades enfrentados em relação à formação inicial; às questões de escassez de tempo; às altas jornadas de trabalho desses profissionais; à falta de recursos para deslocamento e aos custos da formação presencial. Garcia mostrou também que a realização da FCD pode ser simples, com poucos recursos e oferecida pelas universidades públicas de forma gratuita para os professores de ciências. Os cursos podem ser realizados em ambientes de aprendizagem não sofisticados, no entanto desenhados para serem eficazes na modalidade a distância.

Pesquisadores têm procurado compreender as razões que atraem os alunos para a EAD e o perfil (características) dos estudantes bem-sucedidos nesta modalidade de ensino (Keegan, 1996; Gibson, 2003; Palloff; Pratt, 2003; Rurato; Golveia; Golveia, 2007a). Essa compreensão poderia auxiliar os formadores a potencializar a aprendizagem dos alunos e auxiliar, entre outras coisas, na difícil questão da evasão dos cursos.

Schrum e Hong (2002) identificaram sete dimensões que caracterizam os estudantes que são bem-sucedidos em cursos a distância: recursos tecnológicos; experiência tecnológica; estilos de aprendizagem; hábitos e capacidades de estudo; objetivos e finalidades; fatores e estilo de vida; características pessoais. 
Relacionado ao Ensino de Ciências, Garcia (2011) procurou compreender o perfil do professor de ciências que busca a formação contínua a distância para melhorar sua formação, o que o atraí para FCD, quais os fatores que o mantém motivado ao longo dessa formação e suas principais dificuldades. Este autor mostrou que a FCD atrai professores de ciências de ambos os sexos, diferentes idades, formações, tempos de magistério e experiências em EAD. Também foram atraídos professores advindos de escolas públicas e, sobretudo, aqueles com sentimentos negativos em relação à docência e à formação a distância. $\mathrm{O}$ autor mostrou que esses profissionais foram atraídos por motivos pessoais, profissionais e de conveniência. Eles se mantiveram interessados durante o curso por causa do tema, da qualidade das aulas e, principalmente, da criação dos laços afetivos e da sintonia de interesses entre eles e o professor coordenador.

A FCD apresenta aspectos diferentes em relação à formação contínua presencial. Na presencial, via de regra, o formador comanda as ações e o professor apresenta uma postura mais passiva e memorizadora. Essa formação incide sobre o papel e $o$ domínio do formador em detrimento da participação e da análise crítica e reflexiva dos professores. As práticas pedagógicas dos professores mantêm certa distância da formação e podem reforçar o individualismo do professor e colocar obstáculos ao desenvolvimento de uma cultura da cooperação. Por outro lado, no entanto, a FCD requer do professor uma postura mais ativa, participativa, crítica e colaborativa. Aliado a isso características como autonomia e motivação também são necessárias.

De fato, a Educação a Distância apresenta outra cultura educacional, e para o professor de ciências ser bem-sucedido não basta a simples transposição dos modos de fazer e de aprender já incorporados por meio da educação presencial. Participando dessa cultura educacional, o professor de ciências tem encontrado algumas dificuldades em relação ao conteúdo da formação, à administração do tempo de estudos, às novas tecnologias e à organização pessoal. De acordo com Garcia (2011), professores sem experiência na EAD apresentaram maiores dificuldades ao longo do curso em relação à gestão do tempo de dedicação aos estudos, e professores mais jovens, com pouco tempo de magistério e sem experiência em EAD apresentaram maiores dificuldades nas questões pessoais (envolvendo questões como a autodisciplina, a responsabilidade, a organização e a motivação).

Nessa cultura educacional os professores de ciências apresentam também outras preocupações diferentes da educação tradicional. Eles têm outros desafios a enfrentar tanto o processo de estudo a distância como em relação aos investimentos e esforços para participar do curso. Neste sentido, este estudo tem por objetivo investigar as características pessoais, as preocupações, os desafios do processo de 
estudo e os investimentos e esforços de um grupo de professores de ciências que participou, de forma satisfatória (sendo aprovados), de cursos de formação contínua a distância em uma universidade pública.

\section{EDUCAÇÃo A DISTÂNCIA E FORMAÇÃo CONTÍNUA}

A saliência da Educação a Distância nos últimos anos pode ser considerada como um dos resultados da transformação social que vem acontecendo no mundo na chamada "sociedade do conhecimento". É preciso compreendê-la vinculando-a aos acontecimentos da sociedade atual, ao avanço das novas tecnologias e a necessidade de uma Educação Permanente.

Giddens (1991, p.29) define essas transformações promovidas pelas tecnologias utilizando o conceito de "desencaixe", referindo-se "ao deslocamento das relações sociais de contexto locais de interação e sua reestruturação através de extensões indefinidas de tempo-espaço". Essa nova realidade, que lança novas possibilidades ao contexto educacional, ganha concretude na $\mathrm{EAD}$ em geral e na formação contínua de professores a distância em particular.

A EAD é caracterizada, segundo o artigo 1 do decreto $n^{0} 5.622$ publicado Diário Oficial da União (D.O.U.) de 20/12/2005:

como modalidade educacional, pautada em referenciais de qualidade, na qual a mediação didático-pedagógica, nos processos de ensino e aprendizagem, ocorre, nas instituições credenciadas e em seus pólos, com a utilização de meios e tecnologias de informação e comunicação, com estudantes e professores desenvolvendo atividades educativas em lugares ou tempos diversos.

No Brasil, o número de cursos e de instituições de ensino superior oferecendo curso a distância tem crescido. Em 2000, havia 10 cursos oferecidos por instituições autorizadas com 1.682 alunos matriculados. Em 2003, 52 cursos com 49.911 alunos. Em 2006, já existiam 207.206 alunos distribuídos em 349 cursos. E em 2008, esses números subiram para 647 cursos oferecidos e 463.102 alunos matriculados. O crescimento é evidente e perceptível (BRASIL, 2010). Em 2009, segundo dados da ABED (2010), as instituições a distância ministravam 1.752 cursos. Os cursos de especialização formavam o maior grupo (37\%), seguido pelos de graduação (26,5\%), ou então por um grupo que pode ser composto pelos cursos de graduação mais os tecnólogos ou de complementação pedagógica (34,6\%). Os cursos para a formação de professores formavam o maior grupo (31,5\%). 
Os alunos que estudam a distância e são bem-sucedidos apresentam algumas características particulares. Gibson (2003) e Keegan (1996) analisaram estatísticas e índices de sucesso dos alunos que estudam a distância, identificando o perfil mais provável para o sucesso na EAD. Os autores observaram que os alunos são organizados, concentrados, automotivados e maduros. Eles possuem autodisciplina, são autônomos, persistentes, independentes. Possuem flexibilidade e se adaptam facilmente às mudanças.

Esses autores sinalizam que essas características são fundamentais para o aluno obter sucesso na EAD, no entanto, Palloff e Pratt (2003) discutem esse perfil questionando se ele é mesmo do aluno de sucesso. As autoras acreditam que mesmo estudantes que não correspondem completamente a essas características ideais de um aluno virtual possam também ser bem-sucedidos, é necessário, porém, para esses estudantes maior estrutura e apoio no ambiente on-line.

Dentre as principais características dos alunos estão a autonomia e a motivação, que têm recebido atenção por parte dos pesquisadores. A autonomia é uma característica de destaque à medida que o aluno tem de selecionar seus espaços e tempos de estudo e conduzir seu próprio processo de aprendizagem. Ela é a capacidade de se autogovernar e autocontrolar, não dependendo do outro e sendo capaz de tomar as próprias decisões (Piaget, 1977). Martins (2002) afirma que na literatura o tema surge relacionado algumas vezes "à ideia de participação social e, em outros, à ideia de ampliação da participação política no que tange a questões de descentralização do poder” (p. 12).

Moore (2002), em relação à EAD, afirma que a autonomia é considerada a medida pela qual, no processo de ensino e de aprendizagem, é o aluno e não o professor que deve decidir sobre os objetivos e as experiências de aprendizagem. É ele também que tem de tomar as decisões quanto à avaliação do programa de aprendizagem.

A motivação é outra característica importante em relação à EAD. Campos (1989) afirma que ela pode ser considerada um processo interior, no indivíduo, que deflagra, mantém e dirige o comportamento. Ela é um estado fisiopsicológico, um estado de tensão energética, resultante da atuação de fortes motivos que impulsionam a pessoa a agir, com certo grau de intensidade e empenho. A motivação é fundamental para a compreensão de fenômenos internos ao indivíduo, tais como: o comportamento, as atitudes, as aprendizagens, o sucesso em cursos de EAD.

A motivação não é um objeto de estudo diretamente observável. Por esta razão ela tem sido investigada através da análise do comportamento das pessoas. Isto 
visa identificar e compreender os motivos subjacentes às suas inclinações e ações. Embora existam várias concepções sobre a motivação, Murray (1986) afirma que existe um consenso de que é o motivo, como fator interno, que inicia, conduz, mantém e integra o comportamento da pessoa.

O tema tem sido investigado, considerando sua importância, relacionado com a EAD em geral e com a FCD de professores de ciências em particular (Garcia, 2011). A motivação pode, por um lado, potencializar a aprendizagem do aluno e, por outro, auxiliar na delicada questão da evasão dos cursos a distância.

Autores preocupados em manter a motivação do aluno ao longo do curso sugerem a criação de estratégias motivacionais para auxiliar os alunos a permanecerem motivados. Isso poderia ser realizado utilizando materiais de aprendizagem, email e chats (Visser, 2001). Tractenberg (2007) recomenda a cooperação entre docência e discência como fator motivacional e como forma de enfrentar o desafio de ensinar e aprender, recomendando o desenvolvimento de práticas pedagógicas que potencializem a cooperação entre aqueles que estudam a distância. Flores (2009) afirma que o feedback é uma ferramenta fundamental em ambientes virtuais para manter a motivação dos alunos na Educação a Distância. Ou seja, o aluno tem de receber retorno dos formadores ao longo de toda a formação.

Em relação, especificamente, à motivação dos professores de ciências em cursos de FCD, outra forma de motivá-los relaciona-se ao envio de mensagens de encorajamento e de empatia para o desenvolvimento de vínculos afetivos. Garcia (2011) destaca que a criação de laços afetivos entre o formador e o professor de ciências fortalece a motivação e promove a aprendizagem. Isso acontece, sobretudo, através do dialogo constante sobre os interesses e as dificuldades enfrentadas pelos participantes e a busca incessante de formas de atendimento a essas necessidades.

A formação contínua a distância apresenta outra cultura educacional para a formação dos professores de ciências. Nesses espaços o professor tem outras demandas, desafios e preocupações diferentes das formas de estudo presenciais, as quais eles já estavam bem familiarizados.

Nessa cultura educacional, o professor não pode conduzir seu processo de aprendizagem da mesma forma que o faz na educação presencial. Na formação contínua presencial o professor tem um papel passivo, não reflexivo. A formação, geralmente, acontece de forma pontual, fora do contexto de sala de aula, com saberes descontextualizados à prática pedagógica do professor. Esta concepção baseada na racionalidade técnica não se relaciona aos propósitos dos professores e suas práticas 
e enfatizam o individualismo em detrimento da cooperação profissional. Essa formação se centraliza nas deficiências dos professores, no acúmulo de informações, de regras e de conhecimentos. Nóvoa (1991) afirma que a formação do professor não se faz por acumulação através de cursos, de conhecimentos ou de técnicas, mas, sim por meio da reflexão crítica sobre as práticas que ajudam na construção da identidade pessoal. É na reflexão sistemática sobre seu trabalho, nas discussões com seus pares (outros professores ou especialistas em educação), nas dificuldades enfrentadas no cotidiano, que o professor pode encontrar novas possibilidades de ensino e de aprendizagem.

Por outrolado, a formação contínua a distância tem de estar baseada na construção de um profissional prático-reflexivo, um intelectual autônomo. Neste paradigma a prática pedagógica dos professores se caracteriza como o ponto de partida para a formação contínua e não os conhecimentos produzidos pelos especialistas. A partir da reflexão sobre a prática, sobre os problemas do cotidiano é que o professor constrói novas práticas pedagógicas e formas de agir. Esta formação requer do professor autonomia, motivação, participação reflexiva, crítica e criatividade para responder às demandas do curso.

Os professores que participam de cursos de formação contínua a distância apresentam várias preocupações e inquietações, antes e ao longo do curso. $\mathrm{O}$ fato de esses professores trabalharem afeta o tempo para o atendimento das demandas do curso, por exemplo, entregas de trabalhos ou participação de atividades (Garcia, 2011; Silva; Barros; Viana, 2009). Além deste fato, muitos professores apresentam dificuldades para administrar o tempo para os estudos, o que acaba gerando mais preocupações.

Os professores têm também outros desafios na FCD em relação ao processo de estudo a distância. O processo de estudo a distância demanda do professor investimentos de tempo e dedicação à aprendizagem. Esforços para aprender muitas vezes após um dia exaustivo de trabalho aliado às exigências dos afazeres domésticos.

Garcia (2011) ao investigar a gestão da aprendizagem de um grupo de professores de ciências que participou de cursos de formação contínua a distância mostrou algumas estratégias utilizadas por eles para lidar com os desafios do processo de estudo na formação. Esses profissionais tinham um tempo de dedicação semanal ao curso que girava em torno de duas a três horas, com uma "frequência" semanal variando entre duas a três vezes; com uma preponderância de estudos no período da noite, durante a semana e, prioritariamente, de manhã e a tarde nos fins de semana; com o local mais utilizado para acompanhar o curso sua própria casa; utilizando 
técnicas para estudos ligadas às atividades de leitura, sendo a internet e o professor coordenador as maiores fontes de auxílio para dirimir as dúvidas.

\section{O CURSO DE FORMAÇÃo CONTÍNUA PARA PROFESSORES DE CIÊNCIAS}

O curso, gratuito, foi promovido pelo grupo de pesquisa "Ensino de Ciências e Educação a Distância” da Faculdade de Educação da Universidade de São Paulo. Seu objetivo era o de atualizar os professores de ciências que atuam no Ensino Fundamental na temática nutricional.

De acordo com o Programa Oficial do Curso, o objetivo relacionava-se à atualização dos professores de ciências a partir de elementos familiares aos alunos do Ensino Fundamental, explorando a então recente legislação sobre rotulagem de alimentos. Foram abordadas as atuais modificações das normas da Agência de Vigilância Sanitária (ANVISA) que disciplina a rotulagem de alimentos, bem como recomendações de consumo de alimentos, a fim de proporcionar ao professor da disciplina Ciências elementos teórico-práticos suficientes para lidar com a tradicional prática de estudar rótulos de alimentos industrializados em sala de aula (Feusp, 2007).

O curso teve a duração de nove semanas, sendo uma aula por semana e a última de revisão. A carga horária total foi de 60 h. Desse total de horas, 58 foram realizadas a distância, compreendendo acompanhamento das aulas, estudos, participação, seção de perguntas e respostas, desafios, situações-problemas, pesquisa, realização do trabalho escrito, e duas horas presenciais para a prova final em uma das unidades da Universidade de São Paulo. O curso disponibilizava cerca de 120 vagas para professores que estivessem, efetivamente, ministrando aula no Ensino Fundamental.

A estrutura do curso contou com um sítio na internet para a interação dos professores, onde estavam armazenadas oito (8) videoaulas e slides Power-Point referentes à cada aula. As videoaulas apresentavam conteúdos contextualizados por meio de problemas, desafios, a fim de conduzir o professor de ciências à busca de soluções. Elas eram disponibilizadas semanalmente aos professores, assim como o material de apoio, que o professor pode imprimir se desejar.

A estrutura metodológica das videoaulas incluía questões como "atividade de casa" que eram discutidas e corrigidas no início da aula seguinte. Este dispositivo objetivava criar novas expectativas nos professores em relação ao novo conteúdo e, ao mesmo tempo, incentivar a participação nos desafios propostos. Essas aulas 
também apresentavam pesquisas relacionadas à realidade conhecida ou vivida pelos professores de ciências.

Ainda sobre as metodologias existiam formas de interação com sessões "tiradúvidas" e discussões em horários estabelecidos previamente. Isto realça a interação e a aprendizagem colaborativa, objetivando manter sincronia entre os professores. A principal estratégia para manter certa sincronia no trabalho dos professores denominava-se "pergunta relâmpago". Esta tinha caráter participativo, sendo caracterizada como um desafio com horário programado, geralmente no fim de semana. Ao ser transmitida, o participante tinha um tempo limite para responder.

A troca de email do curso foi gerenciado pelo "Google Mail" (www.gmail.com), que é o serviço de webmail da empresa Google. Na primeira versão do curso, em 2007, num período de pouco mais de dois meses, foram trocados mais de 1300 e-mails entre o formador e os professores de ciências.

A participação do professor acontecia, ao longo do curso, entre outras coisas, assistindo às aulas durante a semana, enviando comentários, elaborando perguntas, atuando na solução de desafios propostos e contribuindo com o envio de materiais, dentre outros, textos, tabelas e pesquisas.

A avaliação da formação contínua a distância foi baseada em três instrumentos: a participação no curso, tomando-se como base a qualidade e a pertinência; a prova final presencial, realizada em uma das unidades da Universidade de São Paulo e o trabalho escrito. Em relação à prova final, presencial e individual, esta foi apresentada em três modelos, tinha o valor de 5,0 pontos, e foi composta de 36 questões de múltipla escolha, sem consulta e com duração de duas horas.

\section{METODOLOGIA}

Este estudo investigou as características pessoais, as preocupações, os desafios do processo de estudo e os investimentos (esforços) de um grupo de professores de ciências que participou, satisfatoriamente, de cursos de formação contínua a distância (FCD) em uma universidade pública.

Foram selecionados seis professores e 16 professoras que participavam de cursos de FCD em uma universidade pública. Esses profissionais foram escolhidos, pois participaram do curso, obtendo resultados satisfatórios ao longo da formação e foram aprovados. Visando obter informações mais precisas, esta seleção dos sujeitos se constituiu numa estratégia intencional. Em estudos qualitativos selecionar 
propositadamente os sujeitos é importante para conseguir informações que não poderiam ser agrupadas com outro tipo de escolha. Patton (1990) denominou este dispositivo de "purposeful sampling".

Nos estudos qualitativos, o objeto de estudo é o ponto de partida para a construção do conhecimento e para o desenvolvimento de teorias empíricas. O ponto de vista subjetivo dos sujeitos que estão ligados à pesquisa é fundamental (Flick, 2009). Neste sentido é que a escolha dos sujeitos se torna fundamental.

Foram entrevistados 22 professores no ano de 2007. As entrevistas eram semiestruturadas, com questões abertas, direcionadas e confrotativas (Flick, 2009, p. 149), permitindo certa liberdade, certo direcionamento e certa comparação das respostas dos professores entre as múltiplas perguntas realizadas. Este dispositivo se constitui num mecanismo de triangulação metodológica dentro de um mesmo método, favorecendo a validade dos dados (idem, p. 361-362).

As entrevistas eram compostas de questões sobre: a) o perfil do participante: sexo, idade, formação, nível de educação e experiências com a EAD; b) as características pessoais para estudar a distância; c) as principais preocupações apresentadas ao longo da FCD; d) os desafios do processo de estudo a distância; e) os investimentos e os esforços envidados para a realização de um curso a distância.

Os dados foram analisados sob a abordagem da teoria fundamentada. Este processo de pesquisa consiste na concomitância entre a coleta direcionada de dados e sua análise. Tal situação visa à construção de uma teoria substantiva sobre fenômenos ou eventos sociais. Este tipo de pesquisa se traduz por uma metodologia indutiva de entendimento e transformação de informações em teorias, utilizando, para tal, procedimentos bem definidos (Corbin; Strauss, 1998).

Pandit (1996) e Strauss e Corbin (1998) elencam um conjunto de procedimentos e técnicas para a aplicação do método da teoria fundamentada: desenho do estudo e definição da questão de pesquisa; trabalho concomitante de coleta e análise dos dados; organização para a análise, identificando as categorias conceituais e suas possíveis relações; amostragem teórica e teste das suposições; comparação das suposições com as já existentes na literatura; fechamento, com a refinação da teoria elaborada.

As informações coletadas, neste estudo, foram segmentadas por meio de uma investigação temática. Esta codificação aberta permitiu, num segundo momento, a filtragem dos dados utilizando códigos e descritores (codificação axial). Desta 
forma, foram agrupadas as regularidades, similaridades e diferenças nos dados. Esta conversão e redução permitiram a criação de subcategorias.

\section{RESULTADOS E DISCUSSÃO}

O grupo que participou da pesquisa era formado por professores com média de idade de 33 anos; a maioria (73\%) era do sexo feminino e formado em Biologia (73\%); a maior parte deles (82\%) trabalhava em escolas públicas estaduais. Quanto à experiência em $\mathrm{EAD}, 55 \%$ tinha realizado pelo menos um curso e $45 \%$ não apresentava nenhuma experiência.

\section{As características dos professores de ciências que participam de FDC}

As características pessoais, apontadas pelos respondentes, relacionadas aos professores de ciências para estudar a distância mostraram-se bastante amplas. Elas foram elencadas e revelaram que este professor tem de ser dedicado, persistente, organizado, disciplinado, responsável, interessado, comprometido e, sobretudo, autônomo e motivado.

Os professores sinalizaram que a dedicação ao curso é fundamental em termos de tempo e de esforço pessoal. No entanto, eles apontaram que é preciso ir além e ser persistente para continuar, insistir, ser contumaz nos momentos de solidão do curso ou nos dias em que o cansaço do trabalho sugere uma pausa na formação. Um dos maiores desafios para esse grupo foi se manter motivado ao longo da formação.

Para a FCD é necessário ser organizado e disciplinado para ordenar, arranjar e distribuir o tempo para os estudos, tendo uma metodologia para este trabalho. É fundamental, ao longo da formação, estar aberto para aprender e como citou uma professora "o curso não é obrigatório, você tem de acessar com prazer, o interesse tem de partir do professor que tem de se comprometer com sua própria aprendizagem" (PC5). Por fim, o professor tem de aprender a gerenciar seus estudos de forma autônoma, livre e responsável. Na FCD, o professor tem de ter iniciativa, tem de ser autônomo, pois "é você e o curso, assim o curso tem de valer à pena" (PC4), no entanto "a autonomia tem de ser baseada na responsabilidade do professor" (PC5).

Essas características identificadas são fundamentais para os processos de aprendizagem a distância. Os cursos são mais flexíveis e o professor tem mais liberdade, necessitando de iniciativa para aprender e tomar decisões. Tal situação implica, sobretudo, numa maior responsabilidade com sua própria aprendizagem. 
Características como organização, concentração, motivação, disciplina e autonomia, dentre outras, já tinham sido identificadas por pesquisadores (Keegan, 1996; Gibson, 2003) que buscavam o aluno de sucesso na EAD. Portanto, não há muita diferenciação nas características pessoais de alunos que estudam a distância de diferentes idades, níveis de ensino e tipos de curso e os professores de ciências que realizaram cursos de FCD.

Se essas características são determinantes para o professor de ciências realizar cursos de FCD, melhorar sua formação e, consequentemente, o Ensino de Ciências, poder-se-ia concluir que aqueles que não apresentassem tais peculiaridades estariam impedidos de estudar a distância. Tal fato, no entanto, não se constitui em uma premissa válida, pelo menos não para todos os cursos de FCD. Se o professor de ciências não apresentar todas essas características os formadores devem despender um tempo maior organizando e construindo estratégias para esse professor tanto em termos de orientação como de atividades. Isso deve acontecer desde o início do curso.

Garcia (2011) sugeriu atenção especial com professores que apresentam dificuldade durante o curso, recomendando estratégias mais individualizadas. Palloff and Pratt (2003) observaram "que quanto mais jovens os alunos, ou quanto mais baixo o nível educacional (isto é, aluno de graduação versus aluno de pósgraduação), maior será a estrutura necessária no ambiente on-line” (p. 28).

As características aqui identificadas fornecem elementos para os formadores em cursos de formação contínua a distância, no entanto elas não podem ser interpretadas como elementos impeditivos àqueles professores de ciências que não dispõem de tal perfil.

\section{As preocupações dos professores na FCD}

As principais preocupações apresentadas pelos professores de ciências envolvidos nos cursos de formação contínua a distância foram agrupadas em cinco subcategorias. Estas estão relacionadas às exigências da formação, às expectativas em relação ao sucesso no curso, ao processo de interação no curso, aos conhecimentos adquiridos e às tecnologias. $\mathrm{O}$ quadro 1 sintetiza os resultados: 


\begin{tabular}{|c|l|}
\hline Subcategorias & \multicolumn{1}{|c|}{ Preocupações } \\
\hline $\begin{array}{c}\text { Exigências da } \\
\text { formação }\end{array}$ & $\begin{array}{l}\text { Relacionadas ao planejamento pessoal, ou seja, em como se organizar em } \\
\text { termos de horários semanais e de rotina para este tipo de modalidade de } \\
\text { ensino, considerando as atividades pessoais e profissionais e, sobretudo, } \\
\text { preocupações ligadas ao tempo para participar das atividades elencadas. }\end{array}$ \\
\hline $\begin{array}{c}\text { Expectativas } \\
\text { em relação ao } \\
\text { sucesso no curso }\end{array}$ & $\begin{array}{l}\text { Relacionada à conclusão do curso de forma satisfatória e a não finalizar } \\
\text { o curso pela falta de experiência neste tipo de modalidade de ensino. }\end{array}$ \\
\hline $\begin{array}{c}\text { Expectativas } \\
\text { sobre o processo } \\
\text { de interação }\end{array}$ & $\begin{array}{l}\text { Relativas às ações, a como agir nas discussões com o grupo e com o } \\
\text { formador e como atuar em caso de dúvidas. }\end{array}$ \\
\hline $\begin{array}{c}\text { Expectativas } \\
\text { sobre os } \\
\text { conhecimentos } \\
\text { adquiridos }\end{array}$ & $\begin{array}{l}\text { Quanto ao valor desse conhecimento que será adquirido. Ou seja, se esse } \\
\text { seria útil para vida pessoal e, sobretudo, profissional com os alunos nas } \\
\text { escolas. }\end{array}$ \\
\hline $\begin{array}{c}\text { Expectativas } \\
\text { sobre as } \\
\text { tecnologias }\end{array}$ & $\begin{array}{l}\text { Relacionada à familiarização com as ferramentas tecnológicas para o } \\
\text { acompanhamento do curso. }\end{array}$ \\
\hline
\end{tabular}

Quadro 1. Preocupações dos professores ao longo do curso

É importante citar que as preocupações apresentadas por esse grupo de professores foram sendo dirimidas à medida que eles ampliavam a familiarização com o curso, com o professor coordenador, criando novas formas de fazer para lidar com as demandas da formação.

Os professores de ciências apresentaram preocupações relacionadas às exigências da formação, sobretudo, em termos de tempo para participar das atividades. Mas, eles também tiveram preocupações ligadas às expectativas em relação ao sucesso no curso, ao processo de interação no curso e aos conhecimentos adquiridos.

Essas preocupações estão associadas à participação do professor na formação, e uma das mais comuns em cursos de EAD relaciona-se ao tempo. Silva, Barros e Viana (2009) afirmaram que professores cursistas se preocupam com o fato da participação em um curso online acontecer paralelamente ao período de trabalho, dificultando a efetivação das atividades em tempo hábil. Acrescido a falta de tempo para a participação neste tipo de modalidade de ensino, esses participantes, geralmente, apresentam sobrecarga de trabalho, incluindo questões dos afazeres domésticos (Branco; Oliveira, 2008), o que também interfere no tempo livre para a dedicação aos estudos. 
Esse problema da falta de tempo é, muitas vezes, agravado pelo fato de que muitos professores de ciências que participaram dos cursos de FCD, e que foram entrevistados, não possuíam uma organização pessoal satisfatória, que éfundamental para este tipo de modalidade de ensino. Ou seja, não apresentavam uma rotina para os estudos e não dispunham de uma coordenação de horários (tempo e espaços) para atender as exigências do curso. Os cursos de FCD para professores de ciências necessitam, portanto, de orientações claras em relação ao tempo de dedicação ao curso. Sem uma organização satisfatória, o professor pode, encontrando dificuldades com as demandas, se desmotivar e, até mesmo, desistir da formação.

Notou-se também que os professores tinham preocupações quanto à conclusão do curso de forma bem-sucedida. Este fato pode ser explicado considerando que esses profissionais são adultos, apresentam vivências diversificadas e temem fracassar na formação. Este fracasso, para o adulto, é tomado com um atentado a sua imagem pessoal (Ferreira, 1985). Como afirmou uma professora "preciso ser aprovada no curso e isso tem me deixado apreensiva e preocupada. Sabe este curso é na USP e não poderei dizer aos colegas onde trabalho que fui reprovada num curso da minha área na USP” ( $\left.\mathrm{PC}_{7}\right)$.

Algumas preocupações se relacionaram às formas de interação, traduzindo-se em como conversar ou interagir com os colegas e com o professor formador. No depoimento do PC14 ele afirma que "no início do curso eu estava meio perdido sem saber como conversar com os outros ou com o formador. Eu não sabia nem sequer como pedir ajuda. Na escola normal a gente falava direto com o professor e recebe a resposta na hora, mas aqui é diferente, tive de montar um planinho para este tipo de trabalho". Isso demonstra sua preocupação com o processo de interação. A interação é um fenômeno complexo, dialético e interacionista, envolvendo e, ao mesmo tempo, dependente de elementos e dos contextos, dos indivíduos e dos espaços, constituindose numa ferramenta valiosa para a construção do conhecimento (Ferreira; Rezende, 2004).

As preocupações no estudo a distância demonstradas por esses professores podem ser compreendidas, entre outras coisas, porque o estudo a distância, potencializado pelas tecnologias, requer tanto do formador como do aluno (professor) novas habilidades e formas de compreender o processo de ensino e aprendizagem como um todo, incluindo novas as formas de agir. Tal fato, evidentemente, lança novos desafios para os formadores em termos da criação de novas orientações, de sucessivos diálogos e de criatividade, e para os alunos, que necessitam de novas formas de fazer e aprender. 
Conhecer essas preocupações significa que os formadores podem avançar atendendo as necessidades dos professores de ciências em cursos de FCD, respeitando essas preocupações, adequando-as à organização e estrutura do curso, pois através das atividades do curso é que podem ser gerenciadas as divergências, os conteúdos, os tempos ajustamento (Moran; Masetto; Behrens, 2002).

\section{Os desafios do processo de estudo a distância para professores de ciências}

No processo de estudo a distância ressalta-se o depoimento de um professor quanto à FCD quando ele afirma que esta "é diferente, a gente estranha no início quando se está sozinho, temos de correr atrás, se organizar, pois não há ninguém nos controlando". Em outro trecho ele coloca que o curso "requer da gente outra postura enquanto aluno, você não tem preocupações em relação às faltas, o dia que não se está bem não precisa ir até a faculdade, mas tem de ter responsabilidade, senão você abandona o curso" ( $\left.\mathrm{PC}_{3}\right)$.

Os maiores desafios enfrentados pelos professores para conduzir, satisfatoriamente, o processo de estudo a distância estão relacionados com a organização, a disciplina e a autonomia.

O primeiro desafio no processo de estudos mencionado pelos professores se associa à organização, onde é preciso planejar horários semanais para o estudo, e como afirmou um dos participantes "se não se programar para fazer as aulas no prazo a coisa embola. Você tem de ter também, sabe, um local apropriado para os estudos, livre de barulhos e onde você pode ficar sozinho" (PC1). Nesta organização, o mesmo professor sugeriu que é necessário criar certas rotinas de estudo, tais como: assistir as aulas, fazendo anotações sobre as ideias principais; realizar os exercícios anotando as dúvidas para encaminhar ao formador; pesquisar na internet e em livros para aprofundar em certos temas; interagir com os participantes como o desejo de aprender mais e não ter medo de se expor.

A organização, no processo de estudos, pressupõe também um arranjo de preferência no próprio computador. É preciso criar áreas de estudos, pastas para arquivar as aulas e o material como as mensagens e os textos recebidos. Alguns professores criaram uma biblioteca virtual para a organização pessoal. É necessário também familiarização com os recursos da EAD e a criação de certas rotinas para interagir com os outros professores e também com o formador, utilizando para tal o email, a videoconferência, o telefone. 
Em relação ao segundo desafio, manter a disciplina ao longo da formação, os professores mencionaram que sem ela é difícil acompanhar, participar e realizar as tarefas do curso. A disciplina requer "um mínimo tempo de dedicação, saber que você tem de fazer mesmo (estudar) e não tem ninguém te controlando e que isto é para você" (PC1).

O terceiro desafio, a ser superado no processo de estudos, se relaciona à autonomia. Esta, evidentemente, se torna importante à medida que deve induzir o professor a lidar tanto com a disciplina como com a organização. A autonomia, no entanto, deve ser compreendida num sentido mais amplo, pois faculta ao professor a definição e a condução de sua própria aprendizagem, assim como a criação de novas formas de fazer para atender as demandas da formação.

A autonomia é um processo em constante desenvolvimento, mas é preciso que o formador auxilie o professor de ciências nesta construção. Neste sentido, alguns autores afirmam que existe uma relação entre a estrutura do programa apresentado para o aluno, as mídias que serão utilizadas e o nível de diálogo entre os envolvidos na EAD e o nível de autonomia disponível e experimentado pelo estudante na EAD (Moore, 2002; Barreto, 2011).

É preciso, neste processo de estudo a distância, como afirma a PC20 "correr atrás, ser independente, estabelecer relações entre o que se aprende e realidade de trabalho, buscando uma adequação disso com suas necessidades"; é necessário que o professor "crie, invente formas para dar conta do curso, aproveite todas as oportunidades de aprendizagem, troque experiências, contribua nas discussões, tire as dúvidas e tente aplicar o que você aprendeu. Aqui não tem jeito você tem de ser autônomo" (PC16).

Nos cursos de EAD o aluno deve ser movido para a autonomia, podendo selecionar as formas de estudo, o tempo e o espaço, no entanto Litwin (2001) adverte que essa não pode ser confundida com autodidatismo. $\mathrm{O}$ autodidata é o aluno que seleciona os conteúdos para o estudo e não dispõe de uma proposta pedagógica e didática.

\section{Os investimentos e esforços realizados por professores de ciências para a FCD}

Os professores sinalizaram que existem vários investimentos em termos de esforços para o professor participar de um curso de formação contínua a distância. Destacam-se dois domínios identificados nos depoimentos dos professores: odomínio 
do investimento intelectual e o do emocional. Foi identificado também esforços no sentido de equacionar tempo para o curso em virtude das outras demandas.

No domínio intelectual, os esforços se concentraram na aprendizagem de novos conhecimentos e novas habilidades e na construção de um sentido daquilo que se aprende para o trabalho profissional. O PC11 comentou "que é preciso aprender e mudar o que você já sabia anteriormente para aplicar com os alunos".

No domínio emocional, os esforços se relacionaram ao equilíbrio entre as demandas da família e dos estudos, sobretudo nos relacionamentos com a esposa e com os filhos; do lazer e de questões do curso e do trabalho e dos estudos.

Em relação ao tempo, os esforços estão relacionados à organização de um horário adequado, considerando as demandas de trabalho, família, estudos, lazer. Muitas vezes, os alunos de EAD adotam o período da noite para os estudos, por trabalharem durante o dia (Eliasquevinci; Fonseca, 2006, p.8).

Garcia (2011) mostrou que professores de ciências utilizavam, predominantemente, o período da noite para a dedicação aos estudos. Isto segundo o autor pode estar atrelado ao fato de os professores, na maioria, trabalharem durante o dia. No entanto, é preciso considerar que muitos desses docentes eram casados e tinham filhos, o que representava uma demanda extra, muitas vezes, no período da noite. Esse pode ser um dos motivos que explica as razões de alguns professores cursistas utilizarem o turno da madrugada para se dedicar aos estudos (p. 196).

Não são poucos os esforços para aqueles professores de ciências que querem se envolver em cursos de FCD. Novas aprendizagens, exigências intelectuais e emocionais que atingem a vida pessoal e profissional do professor. Permeando e interligando estes domínios está a questão das demandas de tempo. Os professores relataram grandes investimentos de tempo para participar do curso em detrimento de outras atividades sociais. A administração do tempo, em cursos de FCD, é tarefa do professor e sendo o curso marcado por muitos momentos individuais esta organização é fundamental.

\section{CONSIDERAÇÕES E IMPLICAÇÕES FINAIS}

A investigação sobre investimentos (esforços) realizados pelos professores de ciências que participaram de cursos de formação contínua a distância, sobre os desafios do processo de estudo, sobre as preocupações e as características pessoais, 
além de ampliar os estudos de Garcia (2011), pode auxiliar os formadores na gestão da FCD e potencializar o aprendizado do professor. Os resultados encontrados neste estudo favorecem também o planejamento de novos cursos de FCD. Estratégias individualizadas podem ser construídas para os professores com dificuldades de organização, motivação e autonomia, e orientações mais precisas em relação aos desafios de estudo dessa cultura educacional podem ser direcionadas no início do curso.

Realizar um curso de formação contínua a distância para os professores de ciências exige mais do que investimentos e esforços intelectuais. A realização não se constitui somente no aprendizado de novos conhecimentos para a realização profissional. A FCD demanda do professor esforços emocionais, pois ele precisa equilibrar as exigências de dedicação ao curso, com a família, com o trabalho e com toda vida social, incluindo o lazer. Uma afirmação válida que surge a partir desta pesquisa é que a realização de um curso de FCD para esses profissionais que participaram deste estudo afetou uma vasta rede de relacionamentos pessoais e profissionais.

A participação do professor de ciências em cursos de formação contínua a distância é afetada por suas preocupações, pelo modo como ele lida com seu processo de estudo e pelos investimentos realizados e isso tem implicações em sua aprendizagem ao longo da formação. De fato, a participação pode levar o professor a uma aprendizagem aquém do desejado, a pouca seriedade e dedicação no curso, a criação de uma imagem negativa da FCD e da EAD e, sobretudo, ao insucesso na formação.

As preocupações por serem ocupações mentais antes do real acontecimento, podem, por um lado, ter um efeito negativo e atuar como empecilho para o profissional se organizar na formação. $\mathrm{O}$ excesso delas sem uma estratégia para dirimi-las pode trazer certo quadro de ansiedade e afetar o aprendizado do professor ou até mesmo levá-lo a desistência do curso. Por outro, elas podem potencializar o processo de estudo e os investimentos (esforços), considerando que elas são inquietações que podem colocar o professor em busca de soluções e, sobretudo, motivá-lo na criação de novas formas de fazer requeridas nos cursos de FCD.

O estudo a distância, por fim, implica na aproximação do professor a uma cultura educacional diferente daquela experenciada na educação presencial. Neste contexto, ele enfrenta a situação de ter de definir e conduzir seu próprio processo de aprendizagem. Tal situação, no entanto, se apresenta de forma não familiar, ao menos na primeira experiência, ao que o professor havia experimentado na 
escola tradicional. Isto requer, portanto, mudanças em suas concepções de ensino e aprendizagem e, ao mesmo tempo, a criação de novas formas de fazer para lidar com as demandas deste tipo de modalidade de ensino. Tais mudanças, no entanto, poderiam ser mais equilibradas se os professores de ciências participassem já na formação inicial de disciplinas e/ou cursos que lhe possibilitassem maior familiarização com a EAD e o desenvolvimento de novas competências.

\section{REFERÊNCIAS BIBLIOGRÁFICAS}

Barto, L. S. (2002). A teoria da distância transacional, a autonomia do aluno e o papel do professor na perspectiva de Moore: um breve comentário. Revista Brasileira de Aprendizagem Aberta e a Distância, 1 (2). [em línea] Disponível em: http://www.abed.org. br/revistacientifica/ English/cartas editor/documentos/teoria distancia. $\underline{\mathrm{htm}}$ (consulta 2012, 14 de maio).

Branco, J.C.; Oliveira, M. R. (2008). Educação a distância para professores em serviço: a voz das cursistas. $31^{a}$ Reunião ANPED. [em línea] Disponível em: http://www. anped.org.br/reunioes/31ra/1trabalho/ trabalho16.htm (consulta 2008, 4 de febrero).

Campos, D. M. S. (1993). Psicologia da aprendizagem. 23 ed. Petrópolis: Vozes.

Creswell, J.W. (2002). Educational research: Planning, conducting, and evaluating quantitative and qualitative research. New Jersey: Pearson Education, Inc.

Eliasquevici, M. K.; Fonseca, N. A. (2006). Pontos que facilitam ou dificultam a aprendizagem a distância online: a questão da autonomia. Revista Brasileira de Tecnologia Educacional, Ano. XXXIV.

Faculdade de Educação da Universidade de São Paulo. (2007). Programa Oficial do Curso "Educação Nutricional" a distância.

Ferreira, M. L. R. (1985). A Motivação nos adultos: factor fundamental de aproveitamento no ensino a distância.
SINAL - Revista do Instituto Português de Ensino a Distância, 1, (29-43).

Ferreira, M. M. S.; Rezende. R.S.R. (2003). $\mathrm{O}$ trabalho de tutoria assumido pelo Programa de Educação a Distância da Universidade de Uberaba: um relato de experiência. Seminario ABED 2003. [em línea] Disponível em: www.abed. org?seminãrios2003/testo19.htm (consulta 2012, 18 de agosto).

Flick, U. (2009). Uma introdução à pesquisa qualitativa. 3 ed. Porto Alegre: Bookman.

Flores, A. M. (2009). O feedback como recurso para a motivação e avaliação da aprendizagem na educação a distância. Congresso ABED 2009. [em línea] Disponível em: http://www. abed.org.br/congresso2009/CD/ trabalhos/1552009182855.pdf (consulta 2012, 18 de agosto).

Garcia, P. S. (2011). Formação contínua de professores de ciências: motivações $e$ dificuldades vividas num curso de formação contínua a distância. Tese (Doutorado) - Faculdade de Educação da Universidade de São Paulo, São Paulo.

Giddens, A. (1991). As consequências da modernidade. São Paulo: UNESP.

Gobson, C. C. (2003). Learners and learning: the need for theory. In: Moore, M. G.; Anderson, W. G. (Eds.). Handbook of Distance Education. Mahwah, NJ: Lawrence Erlbaum Associates, (147160).

Keegan, D. (1996). Foundations of Distance Education. 3 ed. London: Routledge. 
Litwin, E. (2001). Educação a distância: temas para debate de uma nova agenda educativa. Porto Alegre: Artmed.

Martins, A. M. (2002). Autonomia da escola: a (ex)tensão do tema nas políticas públicas. São Paulo: Cortez.

Morán, J. M.; Masetto, M. T.; Behrens, M. A. (2002). Novas tecnologias e mediação pedagógica. 5 ed. Campinas, SP: Papirus (Coleção Papirus Educação).

Moore, M. G. (2002). Teoria da distância transacional. Tradução: Wilson Azevedo. Revisão de tradução: José Manuel da Silva. Revista Brasileira de Aprendizagem Aberta e a Distância, 1 (1).

Murray, E. (1986). Motivação e emoção. 5 ed. Trad. de Álvaro Cabral. Rio de Janeiro: Guanabara.

Nóvoa, A. (1991). Concepções e práticas da formação contínua de professores: In: Nóvoa A. (Org.). Formação contínua de professores: realidade e perspectivas. Portugal: Universidade de Aveiro.

Oliveira, D. E. M. B. (2010). Educação a distância: a reconfiguração dos elementos didáticos. Tese (Doutorado em Educação). Universidade Estadual de Maringá, Centro de Ciências Humanas, Letras e Artes, Programa de PósGraduação em Educação. Maringá.

Palloff R. M.; Pratt, K. (2003). The virtual student: A profile and guide to working with on-line students. San Francisco: Jossey-Bass Pfeiffer.

Pandit, N. R. (1996). The Creation of Theory: a Recent Application of the Grounded Theory Method, The Qualitative Report, 2 (4), (1-20).

Patton, M. Q. (1990). Qualitative evaluation and research methods. 2 ed. Newbury Park, CA: Sage.
Piaget, J. (1997). O julgamento moral na criança. Editora: Mestre Jou. São Paulo.

Rurato, P.; Golveia L. B.; Golveia J. B. (2007). As características dos Aprendentes na Educação a Distância: A particularidade de uma análise individualizada. Revista da FCHS, Universidade Fernando Pessoa, 4, (100-117).

Tractenberg, L. (2007). Motivação para o estudo da docência colaborativa online: um novo território a explorar. Congresso $A B E D$ 2007. [em línea] Disponível em: http://www.abed.org.br/ congress02007/tc/562007122423AM. pdf (consulta 2012, 18 de agosto).

Silva, T. A. L.; Barros, J. L. V.; Viana, M. R. G. S. (2009). A questão do tempo na educação on-line: o que pensam os alunos virtuais. In: $19^{\circ}$ Encontro de Pesquisa Educacional do Norte e Nordeste (EPENN) - Educação, Direitos Humanos e Inclusão Social, João Pessoa, 1, (1-16).

Schrum, L.; Hong, S. (2002). From the Field: Characteristics of Successful Tertiary Online Students and Strategies of Experienced Online Educators. Education and Information Technologies, 7 (1), (5-16).

Strauss, A.; Corbin, J. (1998). Basics of qualitative research: techniques and procedures for developing grounded theory. 2 ed. London: Sage Publications.

Visser, L. (2001). Applying Motivational Communication in Distance Learning Support. In: Proceedings of the 17th International Conference on Data Engineering, 2 (6). 


\title{
PERFIL ACADÉMICO Y PROFESIONAL DE LOS AUTORES
}

Paulo Sérgio Garcia. Doutor em educação pela Faculdade de Educação da Universidade de São Paulo (FEUSP). Aluno do programa de pós-doutorado em educação pela FEUSP.

E-mail: garciaps@usp.br

Nelio Bizzo. Livre docente e Professor Titular da Faculdade de Educação da Universidade de São Paulo. Professor dos cursos de pós-graduação da Faculdade de Educação (USP).

E-mail: bizzo@usp.br

Xavier Fazio. PhD in Science Education. Associate Professor, Faculty of Education, Brock University. Ontario, Canadá.

E-mail: xavier.fazio@brocku.ca

DIRECCIÓN POSTAL DE LOS AUTORES

\author{
Rua Monte Alegre, 199, \\ apto 12. São Caetano do Sul (São Paulo). \\ Bairro Santo Antonio. CEP: 09531-110. \\ Brasil
}

Fecha de recepción del artículo: $31 / 03 / 14$

Fecha de aceptación del artículo: 27/04/14

\section{Como citar este artículo:}

Garcia, P. S.; Bizzo, N.; Fazio, X. (2014). Desafios da formação contínua a distância para professores de ciências. RIED. Revista Iberoamericana de Educación a Distancia, volumen $17, \mathrm{n}^{\circ} 2$, pp. 37-57. 